\title{
Radioactive lodine Therapy for Hyperthyroidism Is Associated with Increased Solid Cancer Mortality
}

\author{
Daniel J. Toft \\ Division of Endocrinology, Diabetes, and Metabolism, Department of Medicine, University of Illinois at \\ Chicago, Chicago, Illinois, U.S.A.
}

Review of: Kitahara C, Berrington de Gonzalez A, Bouville A, Brill A, Doody M, Melo D, Simon S, Sosa J, Tulchinsky M, Villoing D, Preston D 2019 Association of radioactive iodine treatment with cancer mortality in patients with hyperthyroidism. JAMA Intern Med. Epub 2019 Jul 1. PMID: 31260066.

\section{SUMMARY}

\section{Background}

Radioiodine (RAI) has been available as a treatment option for patients with hyperthyroidism since the 1940s. The Cooperative Thyrotoxicosis Therapy Follow-up Study (CTTFS) is a large, longitudinal cohort of $>35,000$ patients with hyperthyroidism (due to either Graves' disease or autonomous thyroid nodules) in the United States and the United Kingdom who were treated with RAI between 1946 and 1964. In 1998, data from this cohort demonstrated that RAI therapy for hyperthyroidism was not associated with an increased risk of total cancer mortality (1). As a result, while high doses of I-131 (>14.8 GBq or $400 \mathrm{mCi}$ ) are known to lead to an increase in secondary malignancy (2), the relatively low doses typically used to treat hyperthyroidism have been thought to confer minimal, if any, increased cancer risk based on mortality data. In the current work, the authors extend analysis of the previous CTTFS by including an additional $24+$ years of patient follow-up and by using a new method to attribute organ-based I-131 exposure, in order to assess the associations between RAl therapy for the treatment of hyperthyroidism and site-specific and all-solid-cancer mortality (3).

\section{Methods}

The CTTFS included patients who received RAI treatment for hyperthyroidism at 24 U.S. medical centers and 1 U.K. site between 1946 and 1964. Patients were followed through 1968 with office visits and laboratory measurements; subsequent clinical follow-up was obtained from medical records, patient questionnaires, and national databases that included the U.S. Social Security Administration and the U.S. National Death Index. Of the 35,630 patients in the CTTFS, only the 18,805 RAl-treated patients with complete records (including mortality data through 2014) and who did not have a cancer diagnosis prior to RAl therapy were included in the current analysis.

Organ- or tissue-absorbed doses were estimated using a mathematical model based on data collected from 197 hyperthyroid patients treated with RAI who underwent thyroid, blood, and urine measurements of I-131 (4). Briefly, a standard tissue-compartment model of orally administered iodine uptake, thyroxine formation, and iodine/thyroxine metabolism was used to fit RAl activity measured in the thyroid and blood for the 197 subjects. Patient-specific parameters, such as plasma volume, were calculated using body-mass index, height, and sex; other model parameters were derived from or based on published data. The number of I-131 disintegrations in the various tissue-compartment 


\section{HYPERTHYROIDISM Radioactive lodine Therapy for Hyperthyroidism Daniel J. Toft Is Associated with Increased Solid Cancer Mortality}

models was estimated, and a multivariate regression model was used to correlate measured patient data with I-131 disintegration estimates. Using this multivariate regression model, the tissue-compartment I-131 exposure was calculated for the entire CTTFS cohort on the basis of measured thyroid mass, thyroid uptake, and heart rate. Organ specific I-131 exposure was then estimated using the administered I-131 dose and the compartmental model through a series of assumptions (e.g., the amount of I-131 organ exposure correlates with the fraction of body water space occupied by the organ). Person-years at risk were calculated starting 5 years after I-131 treatment until patient death or the end of the follow-up period. Multivariate linear excess relative risk models per 100 mGy of absorbed I-131 were used to determine tissue-specific cancer risks; variables included age, sex, birth cohort, risk factors, and I-131 dose. Background age- and cause-specific death rates were obtained from U.S. 2014 Surveillance, Epidemiology, and End Results (SEER) data.

\section{Results}

Of the 18,805 patients analyzed, the mean $( \pm S D)$ age at study entry was $49 \pm 14$ years, $78 \%$ were female, and $93.7 \%$ had Graves' disease. The mean total I-131 treatment activity was $375 \mathrm{MBq}(10.1 \mathrm{mCi})$ for patients with Graves' disease and $653 \mathrm{MBq}(17.6$ $\mathrm{mCi}$ ) for patients with autonomous thyroid nodules.
Approximately one third (34.1\%) of the patients received two or more I-131 treatments.

During the mean follow-up of 26 years, statistically significant dose-response relationships for mortality from breast cancer (RR ,1.12; 95\% Cl, 1.003-1.32; $P=0.04)$ and from all solid cancers combined (RR, 1.05; 95\% Cl, 1.01-1.10; $P=0.01$ ) were found. In subgroup analyses, the increased mortality risk from all solid cancers persisted in patients receiving only one dose of I-131 (RR, 1.11; 95\% Cl, 1.02-1.23; P $=0.008$ ); however, that for breast cancer was no longer significant (RR, 0.98; $95 \% \mathrm{Cl},-0.97$ to 1.34 ; $\mathrm{P}>0.5)$. There was no statistically increased risk for deaths related to leukemia, non-Hodgkin lymphoma, multiple myeloma, or thyroid cancer. The authors estimate that $14 \%$ of breast cancer deaths and $7 \%$ of all other solid-cancer deaths were attributed to $\mathrm{I}-131$ exposure in this cohort.

\section{Conclusions}

I-131 dose-dependent mortality from solid cancers was increased in patients (predominantly middle-aged women with Graves' disease) treated for hyperthyroidism. The authors call for additional studies to clarify the risks and benefits of I-131 treatment, surgery, and medical therapy for hyperthyroid patients.

\section{COMMENTARY}

In recent years, there has been growing evidence suggesting an increased risk of secondary malignancies following RAl therapy for thyroid cancer, but the data are quite mixed. Increased incidence of leukemia and salivary gland cancer has been shown in analysis of SEER data (5); analysis of a large Korean cohort of thyroid cancer patients $(>200,000)$ found a dose-dependent increase in leukemia (6); and in a Taiwanese study of $\sim 19,000$ subjects, there were increases in a broad range of cancers, including leukemia, salivary gland, breast, lung, bladder, and brain cancers (7). However, in a recent meta-analysis, an association with leukemia risk was seen for thyroid cancer patients receiving RAl, but there were no significant increases in breast or salivary gland cancers associated with this therapy (8). 


\section{HYPERTHYROIDISM Radioactive lodine Therapy for Hyperthyroidism Daniel J. Toft Is Associated with Increased Solid Cancer Mortality}

In the current work, the authors present updated data on a large cohort of patients with hyperthyroidism treated with RAI. For this trial, an extended follow-up and a refined biokinetic model were developed to estimate tissue-specific I-131 exposure. Strengths of this study include the relatively large sample size, long-term follow-up (range, up to 68 years), and use of a biokinetic model developed specifically for patients with hyperthyroidism. Important limitations include the uncertainty of the accuracy of the biokinetic model in estimating tissue-specific I-131 exposure, the large number of necessary assumptions and statistical analyses (which may introduce chance associations), and the lack of controls for known cancer risk factors such as cigarette smoking, obesity, and estrogen exposure.
Conveying a nuanced interpretation of these data to patients considering treatment options for hyperthyroidism (as well as those previously treated with RAI) will be challenging for clinicians. A review of the risks and benefits of I-131 therapy in the current American Thyroid Association Guidelines for Diagnosis and Management of Hyperthyroidism and Other Causes of Thyrotoxicosis (9) cite a recent meta-analysis of patients treated with I-131 for hyperthyroidism that did not observe an increase in overall cancer mortality, but did note statistically significant increases in kidney and thyroid cancers (10). Additional studies are needed to test the hypothesis that even low doses of RAI, such as those examined in this study, confer an increased risk of mortality.

\section{References}

1. Ron E, Doody MM, Becker DV, Brill AB, Curtis RE, Goldman MB, Harris BS 3rd, Hoffman

DA, McConahey WM, Maxon HR, et al. 1998 Cancer mortality following treatment for adult hyperthyroidism. Cooperative Thyrotoxicosis Therapy Follow-up Study Group. JAMA 280:347355 .

2. Yu CY, Saeed O, Goldberg AS, et al. A systematic review and meta-analysis of subsequent malignant neoplasm risk after radioactive iodine treatment of thyroid cancer. Thyroid. Epub 2018 Nov 27.

3. Kitahara CM, Berrington de Gonzalez A, Bouville A, Brill AB, Doody MM, Melo DR, Simon SL, Sosa JA, Tulchinsky M, Villoing D, Preston DL 2019 Association of radioactive iodine treatment with cancer mortality in patients with hyperthyroidism. JAMA Intern Med. Epub 2019 Jul 1.
4. Melo DR, Brill AB, Zanzonico P, Vicini P, Moroz B, Kwon D, Lamart S, Brenner A, Bouville A, Simon SL 2015 Organ dose estimates for hyperthyroid patients treated with (131)I: an update of the Thyrotoxicosis Follow-Up Study. Radiat Res 184:595-610.

5. Iyer NG, Morris LG, Tuttle RM, Shaha AR, Ganly I 2011 Rising incidence of second cancers in patients with low-risk (T1N0) thyroid cancer who receive radioactive iodine therapy. Cancer 117:4439-4446.

6. Seo GH, Cho YY, Chung JH, Kim SW 2015 Increased risk of leukemia after radioactive iodine therapy in patients with thyroid cancer: a nationwide, population-based study in Korea. Thyroid 25:927934. 
HYPERTHYROIDISM Radioactive lodine Therapy for Hyperthyroidism Daniel J. Toft Is Associated with Increased Solid Cancer Mortality

7. Lu CH, Lee KD, Chen PT, Chen CC, Kuan FC, Huang CE, Chen MF, Chen MC 2013 Second primary malignancies following thyroid cancer: a populationbased study in Taiwan. Eur J Endocrinol 169:577585.

8. Yu CY, Saeed O, Goldberg AS, Farooq S, Fazelzad R, Goldstein DP, Tsang RW, Brierley JD, Ezzat S, Thabane L, et al. 2018 A Systematic review and meta-analysis of subsequent malignant neoplasm risk after radioactive iodine treatment of thyroid cancer. Thyroid. Epub 2018 Nov 27.
9. Ross DS, Burch HB, Cooper DS, Greenlee MC, Laurberg P, Maia AL, Rivkees SA, Samuels M, Sosa JA, Stan MN, Walter MA 2016 American Thyroid Association guidelines for diagnosis and management of hyperthyroidism and other causes of thyrotoxicosis. Thyroid 26:1343-1421.

10. Hieu TT, Russell AW, Cuneo R, Clark J, Kron T, Hall P, Doi SA 2012 Cancer risk after medical exposure to radioactive iodine in benign thyroid diseases: a meta-analysis. Endocr Relat Cancer 19:645-655. 